\title{
ORIGINAL
}

\section{BROTE POR VIRUS DE LA PAROTIDITIS G1 EN LA PROVINCIA DE ALMERÍA EN EL AÑO 2005}

\author{
Pilar Barroso García (1), Ma Ángeles Lucerna Méndez (2), Amparo Navarro Monzón (3).
}

(1) Sección de Epidemiología. Área de Gestión Sanitaria Norte de Almería.

(2) Servicio de Prevención. Empresa Pública Hospital de Poniente (Almería).

(3) Coordinadora de Enfermería. Área de Gestión Sanitaria Norte de Almería.

\section{RESUMEN}

Fundamento: A pesar de que en España se registran coberturas elevadas de la vacuna de parotiditis siguen notificándose brotes epidémicos de parotiditis. El objetivo de este trabajo es describir un brote notificado en la provincia de Almería en el año 2005 y valorar la afectación en población vacunada.

Métodos: Estudio descriptivo de los casos notificados. Variables estudiadas: Zona Básica de Salud, municipio, edad, sexo, tipo de población (autóctona y extranjera), fecha inicio de síntomas, sintomatología, complicaciones, situación vacunal, cepa vacunal y pruebas diagnósticas. Fuentes de información: fichas de declaración de enfermedad, encuestas epidemiológicas, información microbiológica, cartilla de vacunaciones, aplicación informática de vacunas del Distrito y datos demográficos del IEA. Se calcularon tasas por 100.000 habitantes por grupos de edad y tipo de población. Para comparar medias se utilizó la t de Student.

Resultados: Se notificaron 145 casos procedentes de 17 municipios. El 63,4\% fueron varones. El grupo con mayor incidencia fue el de 10 a 14 años con una tasa de 405 por 100.000. La tasa más alta se dio en población autóctona $(128,7)$. En el $52,4 \%$ de los casos se comprobó que habían recibido alguna dosis de vacuna, de ellos $69,7 \%$ con dos dosis y el $71,1 \%$ alguna cepa de Jeryl Lynn. Se confirmó virus de parotiditis en 43 casos, en 6 se identificó genotipo G1.

Conclusiones: Se confirma brote por virus de la parotiditis genotipo G1, con mayor afectación de población autóctona de diferentes grupos de edad. Más de la mitad de los casos fueron personas vacunadas.

Palabras clave: Virus de la parotiditis. Brote epidémico. Vacunación.

Correspondencia:

Pilar Barroso García

Área de Gestión Sanitaria Norte de Almería.

C / Silvestre Martínez de Haro s/n

Huércal-Overa

04600 Almería

Correo electrónico: mariap.barroso.sspa@juntadeandalucia.es
ABSTRACT

\section{G1 Mumps Virus Outbreak in the Province of Almeria in 2005}

Background: Despite high levels of triple MMR vaccinations being recorded on Spain, epidemic mumps outbreaks are still being reported. This study is aimed at describing an outbreak reported in the province of Almeria in 2005 and of evaluating the degree to which the vaccinated population was affected.

Methods: Descriptive study of reported cases. Variables studied: Basic Health District, municipality, age, sex, type of population (Spanish-born and foreign), date of symptom onset, symptoms, complications, vaccination status, vaccine strain and diagnostic testing. Information sources: disease reporting files, epidemiological surveys, microbiological data, vaccination card, District vaccine software and Andalusian Institute of Statistics demographic data. Rates per 100,000 inhabitants were calculated by age groups and population type. The Student's t-test was used for comparing means.

Results: A total of 145 cases from 17 municipalities were reported. A total $63.4 \%$ were males. The group showing the highest incidence was that of 10-14 years of age, with a rate of 405 per 100,000 . The highest rate was among the Spanishborn population (128.7). A total of $52.4 \%$ of the cases were found to have been administered some dose of vaccine, $69.7 \%$ of them with two doses and $71.1 \%$ some Jeryl Lynn strain. Mumps virus was confirmed in 43 cases, the G1 genotype having been identified in 6 cases.

Conclusions: An outbreak of G1 genotype mumps virus is confirmed, the Spanish-born population of different age groups having been affected to a greater extent. Over half of the cases were vaccinated individuals.

Key words: Mumps virus. Epidemic outbreak. Vaccination. 


\section{INTRODUCCIÓN}

En el año 1982 la parotiditis fue considerada como Enfermedad de Declaración Obligatoria en el Sistema de Vigilancia Epidemiológica Nacional. Previamente, en 1981 se había introducido la vacuna triple vírica en el calendario vacunal infantil. En otros países como Inglaterra, Gales y Suiza la introducción de la vacuna se hizo posteriormente ${ }^{1,2}$. El número de casos de parotiditis declarados experimentó en España una disminución progresiva desde el año 1983, con algunos picos epidémicos en los años 1984 y 1989. En el período 1995-1996 se produjo en España un aumento en la notificación de brotes ${ }^{3}$. A partir de 1997 se detectaron algunos casos en niños menores de 10 años, la mayoría vacunados con cepa Rubini ${ }^{4,5}$.

Algunos autores han encontrado que la eficacia vacunal puede oscilar entre un $64 \%$ en niños que reciben una dosis y un $88 \%$ en aquellos que reciben $\operatorname{dos}^{6}$; distintos estudios establecen que con una segunda dosis se logra mayor duración de los niveles de anticuerpos ${ }^{7,8}$. Con respecto a la cepa vacunal se ha registrado menor eficacia de la cepa Rubini que la Jeryl Lynn $^{9,10}$.

En Andalucía en 1984 se puso en marcha el Programa Infantil de Vacunaciones, con dos dosis de triple vírica, una a los 18 meses y otra a los 11 años; a finales de los 90, la cepa Rubini fue sustituida, como en el resto de España, por Jeryl Lynn ${ }^{3,11}$. Además del cambio de cepa se produjeron cambios en el calendario vacunal: a nivel nacional se adelantó la segunda dosis a los 3-6 años de edad ${ }^{3}$ y en Andalucía a los 6 años en el año 1999 y a los 3 en el 2004. Estos cambios en el calendario vacunal infantil y en la cepa vacunal no han evitado que se sigan presentando brotes epidémicos con mayor afectación en población vacunada, como los notificados en Valen- cia y Vizcaya en el año $2006^{11,12}$, a diferencia de otros países, que han presentado mayor número de casos en población susceptible, como los declarados en los últimos años en Inglaterra y Gales ${ }^{1}$, Suecia ${ }^{13}$ o en Reino Unido ${ }^{14}$.

El día 21 de marzo de 2005 se notificó un brote de parotiditis en la Zona Básica de Salud (ZBS) de Los Vélez, la cual pertenece al Distrito Sanitario Levante Alto Almanzora, en la actualidad adscrito al Área de Gestión Sanitaria Norte de Almería, constituida por un total de 7 Zonas Básicas de Salud.

El objetivo de este trabajo es describir dicho brote y valorar la afectación en población vacunada.

\section{SUJETOS Y MÉTODOS}

Se trata del estudio descriptivo de un brote de parotiditis declarado en el Distrito Sanitario Levante Alto Almanzora de Almería en el año 2005. Los sujetos estudiados fueron todos los notificados en el brote. Se utilizaron las definiciones de caso y brote de los protocolos del Sistema de Vigilancia Epidemiológica de Andalucía (SVEA). Se definió brote epidémico como la aparición de 5 ó más casos en una ZBS en 6 semanas. Se consideró caso probable cuando cumplía la definición clínica, se encontraba epidemiológicamente relacionado con otro caso pero sin confirmación de laboratorio. Y caso confirmado si además presentaba test positivo de Ac IgM $\mathrm{o}$ atendiendo a las sugerencias del Centro Nacional de Microbiología (CNM), si había obtenido un resultado positivo en la técnica de amplificación genómica (RTPCR del virus).

Para conocer la situación vacunal de cada caso notificado se comprobó en la cartilla de vacunaciones o en la aplicación informática de vacunas del Distrito Sanita- 
rio si tenía una o dos dosis administradas. Los que indicaban estar vacunados pero no documentados se han considerado como situación vacunal desconocida.

Con respecto a las cepas vacunales, al no aparecer registradas en la aplicación informática no se han podido conocer en cada caso, de ahí que se hayan estimado teniendo en cuenta lo siguiente: fecha de administración de las dosis vacunales; cambios en los calendarios vacunales llevados a cabo en Andalucía; comprobación de que en el Distrito Sanitario en el año 1999 las dos marcas comerciales disponibles correspondían a la cepa Jeryl Lynn. Según esta información se consideró que las dosis administradas anteriores a 1999 eran vacunas con cepa Rubini.

En cuanto a las pruebas diagnósticas para confirmar el agente etiológico al principio, según el protocolo del SVEA, se solicitaron serologías IgM e IgG del virus de la parotiditis. Posteriormente por recomendación del Centro Nacional de Microbiología se solicitó PCR del virus en saliva como en otros brotes ${ }^{12}$. De esta forma, a algunos casos se les solicitó sólo serologías, a otros PCR y a otros ambas. Todas estas pruebas fueron analizadas en el CNM. No en todos los casos notificados se solicitaron pruebas para confirmar el diagnóstico.

Las variables estudiadas fueron: ZBS, municipio, edad, sexo, tipo de población (autóctona y extranjera), fecha de inicio de síntomas, sintomatología, complicaciones, situación vacunal (no vacunado, vacunados con una o dos dosis de vacuna y desconocido), cepa vacunal (Rubini o Jeryl Lynn), y pruebas diagnósticas.

Como fuentes de información se utilizaron: las fichas de declaración de enfermedad, la información microbiológica, la cartilla de vacunaciones, la aplicación informática de vacunas del Distrito y los datos del padrón 2005 publicados por el Instituto de Estadística de Andalucía (IEA). Los datos clínicos disponibles se obtuvieron de encuestas epidemiológicas basadas en el modelo del Centro Nacional de Epidemiología, cumplimentadas por profesionales a los primeros afectados de la ZBS con más casos. Su realización no fue aleatoria, se llevaba a cabo a medida que los afectados acudían al Centro de Salud. Posteriormente no se continuó su cumplimentación porque no aportaba información relevante al estudio del brote.

Se realizó un análisis univariante calculando frecuencias y porcentajes para las variables cualitativas, medianas e intervalos intercuartiles para las cuantitativas; y un análisis bivariante utilizando la t Student para comparar medias. Los datos se analizaron con el Programa SPSS. Se calcularon tasas por 100.000 habitantes por grupos de edad y por tipo de población, utilizando los datos del padrón 2005 (población total de 133.388 habitantes y población extranjera de 23.834 habitantes). No se pudo calcular la incidencia según situación vacunal, dado que no se conocían los datos de cobertura de primera y segunda dosis de todas las cohortes afectadas.

Como medidas preventivas en el brote se realizó búsqueda activa de sujetos susceptibles en contactos próximos y familiares de los sujetos afectados (se consideró población susceptible a los nacidos en el período 1970 a 1985 , con edad aproximada de 20 a 35 años que no hubieran sido vacunados por otros motivos y que no hubieran padecido la enfermedad previamente). En cuanto a la población en edad pediátrica se decidió poner segunda dosis a los niños nacidos entre el 1998 y el 2001 que no la tuvieran administrada, dado que eran las cohortes afectadas por el cambio de calendario vacunal del año 2004 en Andalucía. 


\section{RESULTADOS}

Se notificaron 145 casos de parotiditis, con afectación de 6 ZBS y 17 municipios. 92 fueron hombres $(63,4 \%)$ y 53 mujeres $(36,6 \%)$. Las edades oscilaron entre $1 \mathrm{y}$ 79 años, siendo la mediana de 17 años
(Intervalo intercuartil entre 21-10). El grupo con mayor incidencia fue el de 10 a 14 años con una tasa de 405 por 100.000 (tabla 1). Al realizar el análisis bivariante se encontró que los afectados de la ZBS de Los Vélez $(\mathrm{N}=74)$ tenían una media de edad de 20,7 (DE= 10,1) y los de la ZBS

Tabla 1

Casos de parotiditis notificados según edad y tipo de población

\begin{tabular}{|c|c|c|c|c|}
\hline & Número & Porcentaje & Población & Tasas $\mathrm{x} 100.000$ \\
\hline \multicolumn{5}{|l|}{ Edad } \\
\hline $0-4$ & 12 & 8,3 & 6.383 & 187,99 \\
\hline $5-9$ & 17 & 11,7 & 6.213 & 273,61 \\
\hline $10-14$ & 30 & 20,7 & 7.407 & 405,02 \\
\hline $15-19$ & 31 & 21,4 & 7.898 & 392,50 \\
\hline $20-24$ & 30 & 20,7 & 9.826 & 305,31 \\
\hline $25-29$ & 11 & 7,6 & 11.189 & 98,31 \\
\hline $30-34$ & 7 & 4,8 & 10.962 & 63,85 \\
\hline $35-39$ & 2 & 1,4 & 10.653 & 18,77 \\
\hline$\geq 40$ & 5 & 3,4 & 62.857 & 7,95 \\
\hline Total & 145 & 100,0 & 133.388 & 108,70 \\
\hline \multicolumn{5}{|c|}{ Tipo de población } \\
\hline No extranjeros & 141 & 97,2 & 109.554 & 128,70 \\
\hline Extranjeros & 4 & 2,8 & 23.834 & 16,78 \\
\hline Total & 145 & 100,0 & 133.388 & 108,70 \\
\hline
\end{tabular}

Datos poblacionales correspondientes al padrón de 2005 (IEA).

Figura 1

Número de casos según fecha de inicio de síntomas.

Año 2005

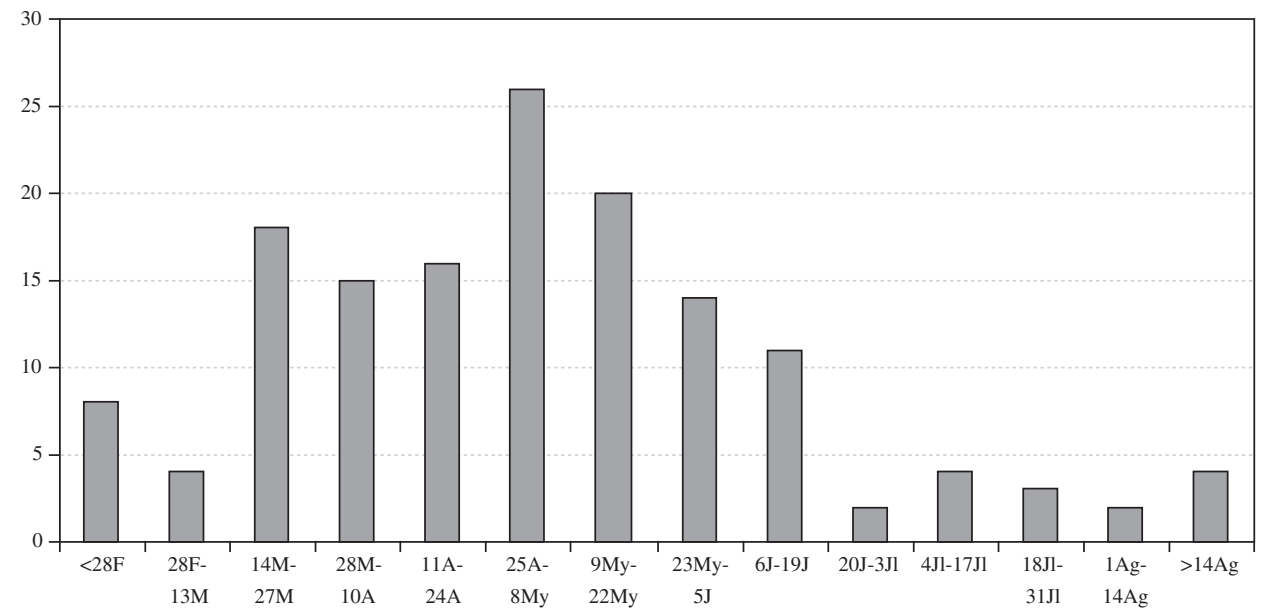


Figura 2

Número casos según situación vacunal

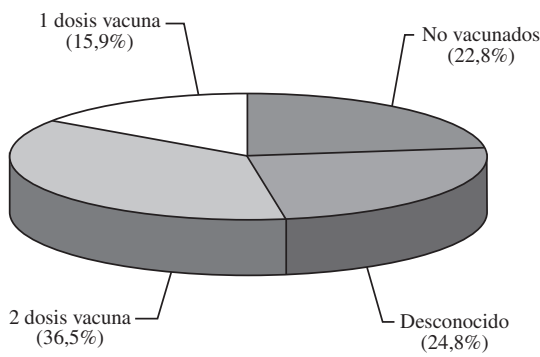

de Mármol $\quad(\mathrm{N}=38) \quad 13,3 \quad(\mathrm{DE}=8,8)$ $(\mathrm{p}<0,001)$. El 97,2\% de los casos correspondió a población autóctona (tasa de 128,7) (tabla 1). El mayor número de casos $(\mathrm{N}=26)$ inició los síntomas en la quincena del 25 de abril al 8 de mayo (figura 1). Con respecto a la situación vacunal 76 casos $(52,4 \%)$ tenían vacuna-
Figura 4

Número casos según cepa vacunal

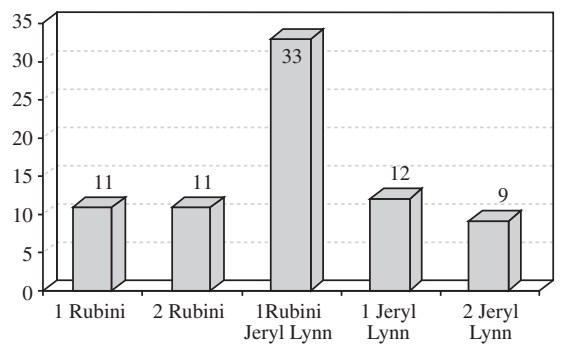

ción documentada, $69,7 \%$ (53 casos) con dos dosis (figura 2). El grupo con mayor número de sujetos vacunados fue el de 10 a 14 años con 29 casos. En los mayores de 24 años no se documentó ninguna dosis (figura 3). El $71,1 \%$ de los casos vacunados tenía administrada al menos una dosis de Jeryl Lynn; un 43,4\% habían

Figura 3

Número de casos según edad y situación vacunal

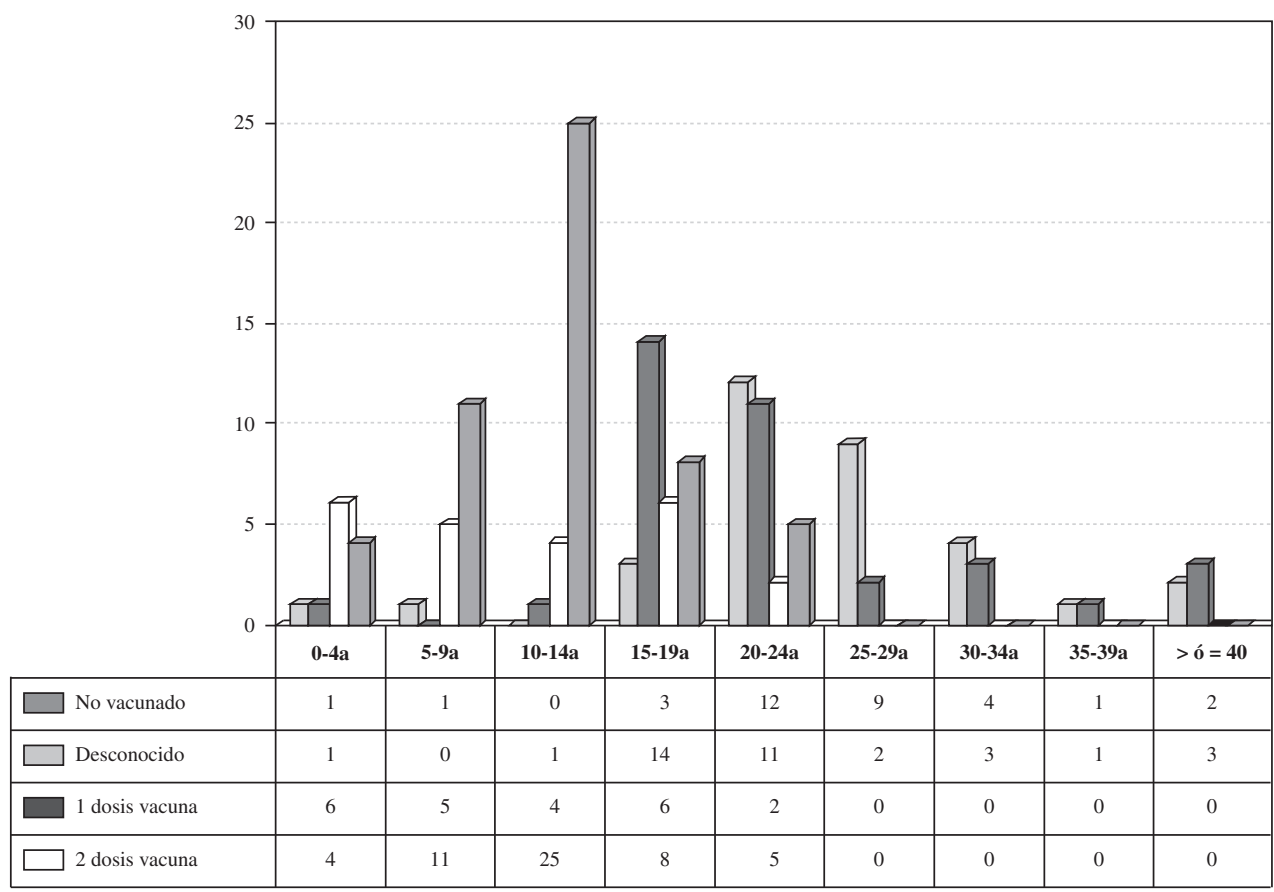


Tabla 2

Distribución de frecuencias de síntomas y complicaciones entre los casos encuestados

\begin{tabular}{|c|c|c|}
\hline Síntomas & $\mathrm{N}^{\circ}$ afectados & $\%$ \\
\hline Inflamación parótida & 40 & $100 \%$ \\
\hline Fiebre & 29 & $72,5 \%$ \\
\hline Cefalea & 15 & $37,5 \%$ \\
\hline Mialgias & 8 & $20 \%$ \\
\hline Anorexia & 6 & $15 \%$ \\
\hline Malestar general & 18 & $45 \%$ \\
\hline Total & 40 & $100 \%$ \\
\hline Complicaciones & $\mathrm{N}^{\circ}$ afectados & $\%$ \\
\hline Orquitis & 3 de 31 & $9,7 \%$ \\
\hline
\end{tabular}

sido vacunados con una cepa de Rubini y otra de Jeryl Lynn y el 11,8\% con dos dosis de Jeryl Lynn (figura 4).
A 40 personas afectadas se les realizó encuesta epidemiológica. El 9,7\% de los hombres encuestados presentó orquitis (tabla 2). Ningún caso precisó hospitalización.

A 69 pacientes se les solicitó analítica. Se solicitaron 59 serologías y 41 determinaciones de PCR (a 10 pacientes sólo PCR, a 31 PCR y serologías y a 28 sólo serologías). Un $50,8 \%$ de las $\operatorname{IgM}$ fueron positivas, $76,9 \%$ en no vacunados. El $91,5 \%$ de las IgG fueron positivas y un $48,8 \%$ de las PCR, para el virus de la parotiditis (tabla 3 ); con un total de 43 confirmados (por serología, por PCR o por ambas), identificándose en 6 de ellos genotipo G1.

Tabla 3

Resultados de las pruebas diagnósticas solicitadas para virus de la parotiditis

\begin{tabular}{|c|c|c|c|c|c|}
\hline & \multicolumn{2}{|c|}{ Positivo } & \multicolumn{2}{|c|}{ Negativo } & \multirow{2}{*}{ Total } \\
\hline & $\mathbf{N}$ & $\%$ & $\mathbf{N}$ & $\%$ & \\
\hline $\begin{array}{l}\text { Ig M } \\
\text { Ig G } \\
\text { PCR }\end{array}$ & $\begin{array}{l}30 \\
54 \\
20\end{array}$ & $\begin{array}{l}50,8 \\
91,5 \\
48,8\end{array}$ & $\begin{array}{r}29 \\
5 \\
21\end{array}$ & $\begin{array}{r}49,2 \\
8,5 \\
51,2\end{array}$ & $\begin{array}{l}59 \\
59 \\
41\end{array}$ \\
\hline \multicolumn{6}{|l|}{ Ig y PCR según situación vacunal } \\
\hline Ig M & 10 & 76,9 & 3 & 23,1 & 13 \\
\hline Ig G & 13 & 100,0 & 0 & 0,0 & 13 \\
\hline $\begin{array}{r}\text { PCR } \\
\text { Jdosis de yacuna }\end{array}$ & 5 & 41,7 & 7 & 28,3 & 12 \\
\hline Ig M & 4 & 57,1 & 3 & 42,9 & 7 \\
\hline Ig G & 7 & 100,0 & 0 & 0,0 & 7 \\
\hline PCR & 2 & 33,3 & 4 & 66,7 & 6 \\
\hline 2 dosis de vacuna & & & & & \\
\hline Ig M & 9 & 37,5 & 15 & 62,5 & 24 \\
\hline Ig G & 22 & 91,7 & 2 & 8,3 & 24 \\
\hline PCR & 5 & 35,7 & 9 & 64,3 & 14 \\
\hline \multicolumn{6}{|l|}{ Ig y PCR según cepa vacunal } \\
\hline 1 Rubini & & & & & \\
\hline $\begin{array}{l}\text { Ig M } \\
\text { Ig G }\end{array}$ & $\begin{array}{l}2 \\
5\end{array}$ & $\begin{array}{r}40,0 \\
100,0\end{array}$ & $\begin{array}{l}3 \\
0\end{array}$ & $\begin{array}{r}60,0 \\
0,0\end{array}$ & $\begin{array}{l}5 \\
5\end{array}$ \\
\hline PCR & 1 & 50,0 & 1 & 50,0 & 2 \\
\hline 1 Jeryl Lynn & & & & & \\
\hline $\operatorname{Ig} M$ & 2 & 100,0 & 0 & 0,0 & 2 \\
\hline Ig G & 2 & 100,0 & 0 & 0,0 & 2 \\
\hline PCR & 1 & 25,0 & 3 & 75,0 & 4 \\
\hline 2 Rubini & & & & & \\
\hline Ig M & 1 & 25,0 & 3 & 75,0 & 4 \\
\hline Ig G & 4 & 100,0 & 0 & 0,0 & 4 \\
\hline PCR & 1 & 50,0 & 1 & 50,0 & 2 \\
\hline 1 Rubini 1 Jeryl Lynn & & & & & \\
\hline $\operatorname{Ig} M$ & 7 & 43,7 & 9 & 56,3 & 16 \\
\hline Ig G & 14 & 87,5 & 2 & 12,5 & 16 \\
\hline PCR & 4 & 36,4 & 7 & 63,6 & 11 \\
\hline 2 Jeryl Lynn & & & & & \\
\hline Ig M & 1 & 25,0 & 3 & 75,0 & 4 \\
\hline $\mathrm{Ig} \mathrm{G}$ & 4 & 100,0 & 0 & 0,0 & 4 \\
\hline PCR & 0 & 0,0 & 1 & 100,0 & 1 \\
\hline
\end{tabular}

Ig: Inmunoglobulina. 
Tabla 4

Evolución de coberturas vacunales por cohortes, tras búsqueda activa

\begin{tabular}{|c|c|c|c|c|c|}
\hline Año & 1998 & 1999 & 2000 & 2001 & Total \\
\hline Número de nacidos & 971,00 & $1.057,00$ & $1.053,00$ & $1.179,00$ & 4260 \\
\hline $2^{\mathrm{a}}$ dosis TV a junio de 2005 & 603,00 & 455,00 & 488,00 & 536,00 & 2082 \\
\hline Cobertura junio $2005(\%)$ & 62,10 & 43,05 & 46,34 & 45,46 & 48,87 \\
\hline $2^{\mathrm{a}}$ dosis TV tras búsqueda activa a diciembre 2005 & 806,00 & 855,00 & 804,00 & 875,00 & 3340 \\
\hline Cobertura diciembre $2005(\%)$ & 83,01 & 80,89 & 76,35 & 74,22 & 78,5 \\
\hline
\end{tabular}

TV: Triple Vírica.

Se vacunó un adulto susceptible y se administró segunda dosis vacunal a 1.258 niños de las cohortes de nacidos entre 1998 y 2001, mejorando la cobertura de un $48,87 \%$ a un $78,4 \%$ a final de diciembre del 2005 (tabla 4).

\section{DISCUSIÓN}

El brote se inició en los municipios de una ZBS, aunque la evolución posterior con afectación de 17 municipios llevó a considerarlo de carácter poblacional. Los síntomas presentados por los primeros casos, con inflamación de la glándula parótida, hicieron sospechar el virus de la parotiditis como uno de los gérmenes más probables, lo que fue confirmado posteriormente por las técnicas de PCR en saliva y aumento de la IgM al virus de la parotiditis. No obstante, en la segunda ZBS implicada, la de Mármol, los afectados eran en general niños con vacunación correcta y las primeras muestras serológicas analizadas de niños vacunados dieron negativo al virus de la parotiditis ( $\mathrm{IgG}$ positiva e IgM negativa). Estos aspectos hicieron que se pensara en la posibilidad de que se tratara de un brote diferente, producido por otro tipo de virus, como ya se había descrito en un estudio realizado en Finlandia, en niños con cuadro de parotiditis vacunados con triple vírica ${ }^{15}$.

El rango de edad fue amplio, similar al de un brote notificado en Suecia, aunque la media fue más baja que en éste ${ }^{13} \mathrm{y}$ en otros notificados en Reino Unido, Inglaterra y Gales $^{1,14}$. La edad ha sido distinta según ZBS, pero superior a la descrita en otros estudios $^{3,8,11,12}$.

Uno de los aspectos que más dificultad dio en el estudio fue conocer la situación vacunal, lo cual ha supuesto algunas limitaciones, ya que no se han podido conocer las coberturas vacunales de primera y segunda dosis de todas las cohortes de afectados y, por lo tanto, tampoco la efectividad vacunal. No fue posible conocer el lote de la vacuna administrada, de ahí que se estimara la cepa vacunal teniendo en cuenta cual se administraba en la zona según el año de vacunación, lo que puede conllevar algún sesgo, dado que algunos de los afectados podían haber sido vacunados en otra zona o que anteriormente a 1999 alguno de los casos hubiese sido vacunado con cepa Jeryl Lynn. Además, la mayoría de los jóvenes no conservaba la cartilla de vacunación y no se encontraron registros en adultos. A pesar de estas limitaciones, se puede afirmar que el número de casos en sujetos vacunados ha sido alto, de forma similar a otros brotes notificados en los últimos años ${ }^{8,11,12} \mathrm{y}$ que un porcentaje importante tenía una o dos dosis de cepa Jeryl Lynn. Este hecho podría deberse a que la eficacia conocida de la vacuna se sitúa alrededor del $80 \%{ }^{16}$, aspecto que podría estar influido por las características del virus, que posee 10 genotipos distintos que pueden variar a lo largo del tiempo según la zona geográfi$\mathrm{ca}^{2,17-20}$. 
El genotipo detectado del brote corresponde al G1, que aunque ya se había aislado en otros países ${ }^{18}$ era distinto a los que estaban circulando en España hasta esa fecha. Posteriormente se detectó también en Valencia $^{12}$ y en Vizcaya ${ }^{11}$.

El brote se inició en población autóctona y las tasas fueron muy superiores para dicha población. Destaca la baja tasa en población extranjera teniendo en cuenta que, según datos del padrón, esta población suponía un porcentaje cercano al $20 \%$, de los cuales el $46 \%$ correspondían a países distintos a los de la Unión Europea, sobre todo Latinoamérica y Asia, en los que cabría pensar que pudieran tener una baja cobertura vacunal, aunque otra posibilidad es que esta población no sea susceptible por haber padecido la enfermedad en su país de origen.

Con respecto a la clínica presentada, el número de casos de orquitis registrados fue menor a los detectados en otros brotes ${ }^{14}$. Hay que tener en cuenta que desde la introducción de la vacuna la orquitis ha disminuido, aunque en algunos países, como Reino Unido, se ha detectado un incremento ${ }^{21}$.

Con respecto al resultado de las pruebas analíticas la positividad fue baja. Algunos trabajos han registrado sensibilidad muy baja de la IgM en sujetos vacunados ${ }^{22}$. En nuestro estudio la proporción de casos confirmados serológicamente fue superior al de otros trabajos $3,13,19$, aunque se han obtenido muchos resultados negativos, mayor en vacunados con 2 dosis que con 1 dosis. La técnica de la PCR es un método diagnóstico rápido para detectar el genoma del virus $^{23}$, es fácil de realizar y no es cruenta, lo que supuso mucha comodidad sobre todo en niños pequeños. A diferencia de otros trabajos que aportaron alta positividad ${ }^{12}$, en este estudio un porcentaje importante tuvo resultado negativo, aunque similar a la aportada para otros brotes ${ }^{13}$, o incluso supe- rior $^{11}$. Esta baja positividad quizás se haya debido a la toma no adecuada de las muestras, bien porque no se haya cogido en el período óptimo (algunos autores han descrito una disminución de la carga viral después del tercer día y también baja carga viral en pacientes vacunados que cursaron con enfermedad leve ${ }^{23}$ ) o porque en nuestro caso la muestra no se ha tomado con escobillón directamente de la salida de la glándula. De esta forma parece que cada vez hay más argumentos a favor de que se pueda realizar, como indican algunos autores, titulación de $\mathrm{IgG}$ frente al virus de parotiditis para el diagnóstico de la infección según el estado vacunal ${ }^{3,22}$.

Las actuaciones de prevención y control se establecieron antes de conocer el agente causal, no obstante, el carácter poblacional del brote entrañó dificultad en cuanto a las medidas preventivas llevadas a cabo, dado que las personas afectadas estaban distribuidas por distintos colegios, institutos $\mathrm{y}$ guarderías o desarrollaban su actividad profesional en todos los municipios implicados, a diferencia de otros brotes de carácter más localizado en centros escolares en los que se pudo trabajar con determinadas cohortes completando dosis vacunales ${ }^{11}$. La vacunación de contactos susceptibles no se realizó ya que o estaban vacunados o indicaban haber padecido la enfermedad en la infancia. Dada la poca afectación en población inmigrante tampoco se llevaron a cabo medidas, influyendo en ello la dificultad que conlleva desarrollar una estrategia en este tipo de población. Por lo tanto, se optó como mejor actuación realizar captación activa en las cohortes vacunadas incorrectamente. Esta decisión se adoptó porque aunque la cobertura de primera dosis era superior al $95 \%$, similar a la estimada a nivel nacional ${ }^{16}$, se notificaron algunos casos en niños con edades comprendidas entre 3 y 6 años que tenían una única dosis de vacuna, cuando por el calendario vacunal ya les correspondían dos. Esto se debió a que estaban afectados por el cambio del calendario 
vacunal producido en el año 2004. Finalmente se consiguió mejorar la cobertura vacunal de estas cohortes, aunque se considera necesario seguir insistiendo para alcanzar una cobertura superior al $90 \%$, necesaria para impedir la transmisión de la enfermedad $^{24}$.

\section{AGRADECIMIENTOS}

A todos los profesionales del Distrito Sanitario de Atención Primaria Levante Alto Almanzora que han participado en la notificación de casos, en la toma de muestras y en la vacunación de la población. A los profesionales del Hospital "La Inmaculada" y del Centro Nacional de Microbiología por su participación en el procesamiento y en el análisis de las muestras.

\section{BIBLIOGRAFÍA}

1. Savage E et al. Mumps outbreaks across England and Wales in 2004: observational study. BMJ. 2005; 330: 1119-20.

2. Utz S, Richard JL, Capaul S, Matter HC, Hrisoho MG Mühlemann K. Phylogenetic Analysis of Clinical Mumps Virus Isolates from vaccinated and non-vaccinated patients with mumps during an outbreak, Switzerland 1998-2000. J Med Virol. 2004; 73: 91-96.

3. De los Ríos Martín R, García Marín N, Sanz Moreno JC, Ballester Orcal E. Parotiditis en un área urbana de la Comunidad de Madrid. Estado vacunal, diagnóstico y medidas de intervención. Aten Primaria. 2001; 28: 10-6.

4. Pons C, Pelayo T, Pachón I, Galmes A, González L, Sánchez C et al. Two outbreaks of mumps in children vaccinated with the Rubini strain in Spain indicate low vaccine efficacy. Euro Surveill. 2000; 5: $80-84$.

5. López B, Martín RM, Román C, Peñalver I, López JA. Brote epidémico de parotiditis. Estudio de la efectividad vacunal. Aten Primaria. 2000; 25 : 148152.

6. Harling $\mathrm{R}$ et al. The effectiveness of the mumps component of the MMR vaccine: a case control study. Vaccine. 2005; 23: 4070-4.
7. Pebody RG, Gay NJ, Hesketh LM, Vyse A, Morgan-Capner P, Brown D et al. Immunogenicity of second dose measles-mumps-rubella (MMR) vaccine and implications for serosurveillance. Vaccine. 2002; 20: 1134-40.

8. Vandermeulen C, Roelants M, Vermoere M, Roseew K, Goubau P, Hoppenbrouwers K. Outbreak of mumps in a vaccinated child population: a question of vaccine failure? Vaccine. 2004; 22: 2713-6.

9. Richard JL, Zwahlen M, Feuz M, Matter HC; Swiss Sentinel Surveillance Network. Comparison of the effectiveness of two mumps vaccines during an outbreak in Switzerland in 1999 and 2000: a case-cohort study. Eur J Epidemiol. 2003; 18: 569-77.

10. Cruz Rojo C et al. Study of the immune response engendered by differents combined measles, mumps and rubella (MMR) vaccines in an area of Andalusia (Spain). Vaccine. 2003; 22: 280-6.

11. Millán Ortuondo E, González Sancristóbal I, López Soria L, Echevarría Mayo JE, de Castro Laiz V, Muniozguren Agirre N. Brote de parotiditis vírica en un colegio de Bizkaia en 2006. Rev Esp Salud Publica. 2007; 81: 33-42.

12. Roig Sena FJ et al. Brote epidémico por virus de la parotiditis genotipo G1. Bol Epidemiol Sem. 2006; 14: 25-36.

13. Sartorius B et al An outbreak of mumps in Sweden, February-April 2004. Euro Surveill. 2005; 10: 191-3.

14. Gupta RK et al. Mumps and the UK epidemic 2005. BMJ. 2005; 330: 1132-5.

15. Davidkin I et al. Etiology of Mumps-Like Illnesses in Children and Adolescents Vaccinated for Measles, Mumps, and Rubella. J Infect Dis. 2005; 191: 719-23.

16. Amela C, Pachon I, de Ory F. Evaluation of the measles, mumps and rubella immunisation programme in Spain by using a sero-epidemiological survey. Eur J Epidemiol. 2003; 18: 71-9.

17. Muhlemann K The molecular epidemiology of mumps virus. Inf Genet Evol. 2004; 4: 215-9.

18. Jin L, Brown DW, Litton PA, White JM. Genetic Diversity of Mumps Virus in Oral Fluid Specimens: Application to Mumps Epidemiological Study. J Infect Dis. 2004; 189: 1001-8.

19. Lee JY, Na BK, Kim JH, Lee JS, Park JW, Shin $\mathrm{GC}$ et al. Regional outbreak of mumps due to 
genotype H in Korea in 1999. J Med Virol. 2004; 73: 85-90.

20. Örvell C, Tecle T, Johansson B, Saito H, Samuelson A. Antigenic relationships between six genotypes of the small hydrophobic protein gene of mumps virus. J Gen Virol. 2002; 83: 2489-96.

21. Masarani M, Wazait H, Dinneen M. Mumps orchitis. J R Soc Med. 2006; 99: 573-5.

22. Sanz JC, Mosquera MM, Echevarría JE, Fernández M, Herranz N, Palacios G et al. Sensitivity and specificity of immunoglobulin $\mathrm{G}$ titer for the diagnosis of mumps virus in infected patients depending on vaccination status. APMIS. 2006; 114: 788-94.

23. Okafuji T, Yoshida N, Fujino M, Motegi Y, Ihara T, Ota Y et al. Rapid diagnostic method for detection of mumps virus genome by loop-mediated isothermal amplification. J Clin Microbiol. 2005; 43: $1625-31$.

24. Nardone A Pebody RG, van den Hof S, LevyBruhl D, Plesner AM, Rota MC et al. Sero-epidemiology of mumps in western Europe. Epidemiol Infect. 2003; 131: 691-701. 